Research Article

\title{
Structures Dynamic Property Analysis of Elastic Composite Cylindrical Rolling Element
}

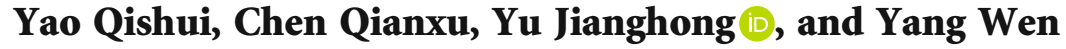 \\ College of Mechanical Engineering, Hunan University of Technology, Zhuzhou 412007, China \\ Correspondence should be addressed to Yu Jianghong; hutyjh@hut.edu.cn
}

Received 24 July 2021; Revised 28 August 2021; Accepted 22 September 2021; Published 18 October 2021

Academic Editor: Paramvir Singh

Copyright (C) 2021 Yao Qishui et al. This is an open access article distributed under the Creative Commons Attribution License, which permits unrestricted use, distribution, and reproduction in any medium, provided the original work is properly cited.

\begin{abstract}
Elastic composite cylindrical roller bearing is a novel type of roller bearing whose rolling element is designed by innovating the rolling element structure of cylindrical roller bearings. For the purpose of investigating the dynamic properties of the rolling elements with different structural parameters and solving the modes of elastic composite cylindrical rolling element with different filling degrees, first, this study compares elastic composite cylindrical rolling element to solid cylindrical rolling element, in terms of natural frequency and vibration mode. Next, the integration time step is determined, based on the natural frequency of the vibration in the Y direction, the response of various rolling element, under impact loads, is solved. Furthermore, the laws of the energy changes and nodal displacement variations of rolling element are explored, at different filling degrees. Finally, adopting the decay method, the damping ratio of elastic composite cylindrical rolling element, under different structural parameters and external loads, is calculated. According to the results, with the increase of filling degree, the natural frequencies of various orders of elastic composite cylindrical rolling element gradually declined. The damping ratio of rolling elements decreased, as the filling degree increased, while it could be changed by adjusting the structural dimensions of rolling elements. The analysis results of this study provide some theoretical reference for studies on the parameter optimization of rolling element structures, the vibration and noise reduction of elastic composite cylindrical roller bearings.
\end{abstract}

\section{Introductions}

Cylindrical roller bearings, by virtue of the linear contact between their rolling elements and inner and outer ring raceways, are characterized by strong loading capacity, high radial stiffness and low friction torque, while they are extensively applied on wind power equipment, printers, NC machine tools and other mechanical equipment. With the development of heavy-duty, high-speed mechanical equipment, the components of cylindrical roller bearings are frequently subjected to excess stress and intense frictional wear, under extreme service conditions, which seriously compromise the reliability and safety of the mechanical equipment [1]. In this context, investigating the performance of cylindrical roller bearings is of vital significance, in improving both the running precision and fatigue life of bearings, as well as the stability of mechanical equipment.
Rolling elements, as core components of roller bearings, transmit loads and motion through interacting with inner and outer rings, retainers and other components. The performance of rolling elements determines the performance of roller bearings, to a very large extent. By investigating the surface geometric characteristics of solid cylindrical rolling element, many scholars have modified their generatrixes, using the crowning technique, aiming to reduce the axial stress of rolling elements, effectively improving the singular distribution of edge pressure, at both ends of rolling elements, as well as strengthening the bearing capacity and fatigue life [2-5]. However, when it comes to processing and manufacturing, the precise modification of cylindrical rolling element profiles requires high process precision and incurs high costs. Some scholars have proposed to design solid cylindrical rolling element as hollow rolling element and leverage their susceptibility to deformation, in order to increase the half-width of contact with raceways, thus 
reducing the contact stress between rollers, inner and outer ring raceways, improving the bearing capacity [6-8]. Since a hollow rolling element has a smaller mass than a solid rolling element with the same volume, this design can also reduce the centrifugal force of the rolling element, in the high-speed running of bearings and increase their limiting speed. The problem is that, for hollow cylindrical roller bearings in long-term service, hollow rolling elements are in a periodic alternate deformation state, while their inner walls are susceptible to bending fatigue fracture, which further leads to the fatigue failure of bearings [9]. In this study, to improve the comprehensive performance of cylindrical roller bearings, the respective rolling element structures were innovated and Polytetrafluoroethylene (PTFE) was embedded into the hollow cylindrical rolling element with a deep hole (chamfer) by means of "sintering", thus preparing the elastic composite cylindrical rolling element. An elastic composite cylindrical roller bearing structure and its rolling element are illustrated in Figure 1 [10]. The outstanding structural design of embedding a high polymer material into a rolling element has improved the stress conditions of the rolling element and other components, strengthened the bearing capacity and fatigue life of bearings, while integrated the advantages of solid and hollow bearings into the structure of the elastic composite cylindrical roller bearings. This integration presents a promising prospect for engineering applications $[11,12]$. In view of the special structure of elastic composite cylindrical rolling element, this study investigated their dynamic properties and performed modal solving for elastic composite cylindrical rolling element with different structural parameters, based on explicit dynamics theory, using the finite element method. It also explored the dynamic responses of elastic composite cylindrical rolling element under impact loads and compared them to solid cylindrical rolling elements. The analysis results of this study offer some theoretical reference for future studies on elastic composite cylindrical roller bearings and related engineering applications.

In view of the special structure of elastic composite cylindrical rolling element, this study investigated their dynamic properties, performed modal solving for elastic composite cylindrical rolling element with different structural parameters, based on explicit dynamics theory, using the finite element method. It also explored the dynamic responses of elastic composite cylindrical rolling element under impact loads and compared them to solid cylindrical rolling elements. The analysis results of this study offer some theoretical reference for future studies on elastic composite cylindrical roller bearings and related engineering applications.

\section{Modal Analysis on Elastic Composite Cylindrical Rollers}

2.1. Construction of the Finite Element Model. In this study, the embedding rate of PTFE in the rolling element was adopted to define filling degree $K=d / D$ (where $D$ is the outer diameter of the roller and $d$ is the respective parameter of the embedded PTFE) $[13,14]$. The specific parameters of N310 elastic composite cylindrical rolling element were selected with reference to GB/T283-2007. Specifically, the rolling elements were set with a length $L$ of $13.5 \mathrm{~mm}$ and a diameter $D$ of $15 \mathrm{~mm}$. Considering the symmetry of the rollers, the $1 / 2$ point of the structure, in the radial direction, was selected to build finite element models for solid rolling elements (filling degree $K=0 \%$ ) and elastic composite cylindrical rolling element with filling degrees of $40 \%, 50 \%$ and $65 \%$, using the software ABAQUS. 3D models for solid rolling elements and elastic composite cylindrical rolling element with a filling degree of $60 \%$, are illustrated in Figure 2.

In terms of material attributes, the metal part of the rollers used GCr15 with an elastic modulus of $2.07 \times 10^{5} \mathrm{MPa}$, a Poisson's ratio of 0.3 and a density of $7,850 \mathrm{~kg} / \mathrm{m}^{3}$. The elastic modulus, Poisson's ratio and density of PTFE were 280 $\mathrm{MPa}, 0.4$ and $2,200 \mathrm{~kg} / \mathrm{m}^{3}$, respectively. In terms of meshing, eight-node hexahedral elements were used, according to the structural characteristics of various rolling elements, while the mesh density values of their finite element models were properly controlled to guarantee calculation precision [15].

As far as the precision of modal solving is concerned, it is of great importance to set reasonable boundary conditions for the rolling elements. In this study, on the basis of rolling element running in the service of bearings, the motion degrees of freedom in the $\mathrm{Z}$ direction, on the two end faces of each model, as well as that in the Y direction, on the bottom edge $\mathrm{AB}$, were constrained. Meanwhile, considering the symmetry of the rolling elements, symmetric constraints were also applied on the section ABCD of each model.

2.2. Analysis Results and Discussion. After the construction of finite element models for various rolling elements, modal solving was performed, using the Block Lanczos method, to obtain the modes of various orders of solid rolling elements and elastic composite cylindrical rolling element with filling degrees of $40 \%, 50 \%$ and $65 \%$. Considering that, system vibration mainly depends on the natural frequencies of low-order modes and the natural frequencies of high-order modes have a non-significant effect on system vibration. According to reference $[14,16]$ on the study of modal shapes, the modes of the first six orders were selected for analysis for each model. The natural frequencies of the modes of the first six orders are listed in Table 1. These data showed that the vibration modes of various rolling elements were basically consistent, while the natural frequencies of solid cylindrical rolling elements and elastic composite cylindrical rolling element, with different filling degrees, all increased along with the rise of the order number of vibration modes. This occurred because, under a higher order number of vibration modes, the energy exciting the highorder vibration loads of the rolling elements was weaker and the node number of vibrations was higher, which made it more difficult to excite vibration. The natural frequencies of various orders of solid cylindrical rolling element were higher than those of elastic composite cylindrical rolling element. With the increase of filling degree, the natural frequencies of various orders of elastic composite cylindrical rolling element gradually declined. 


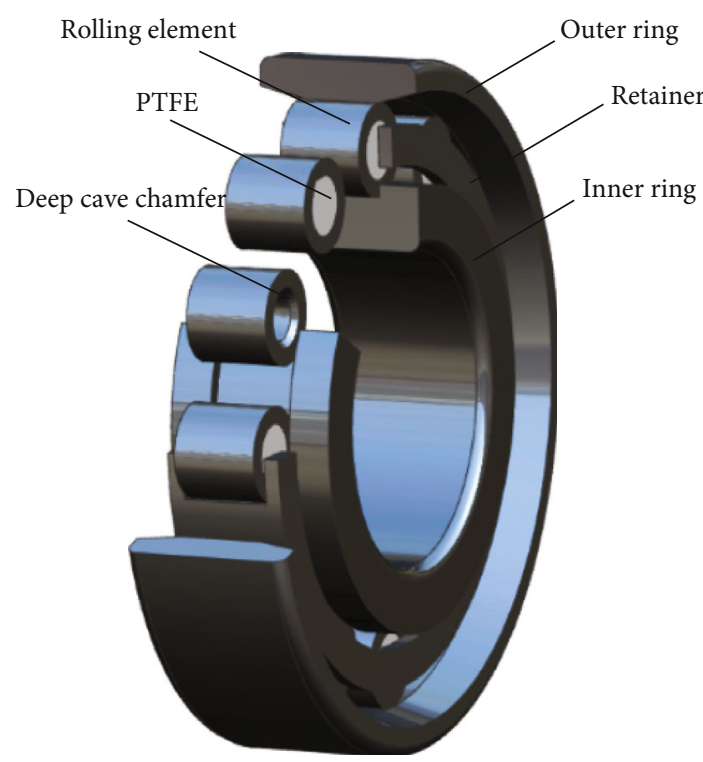

(a) Elastic composite cylindrical roller bearing structure

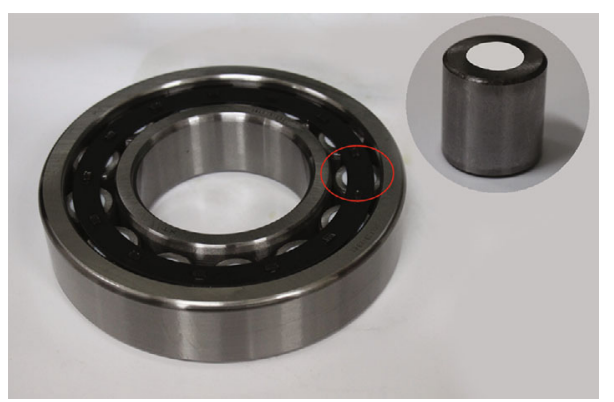

(b) Elastic composite cylindrical rolling element structure

FigURE 1: Elastic composite cylindrical roller bearing structure and its roller element.

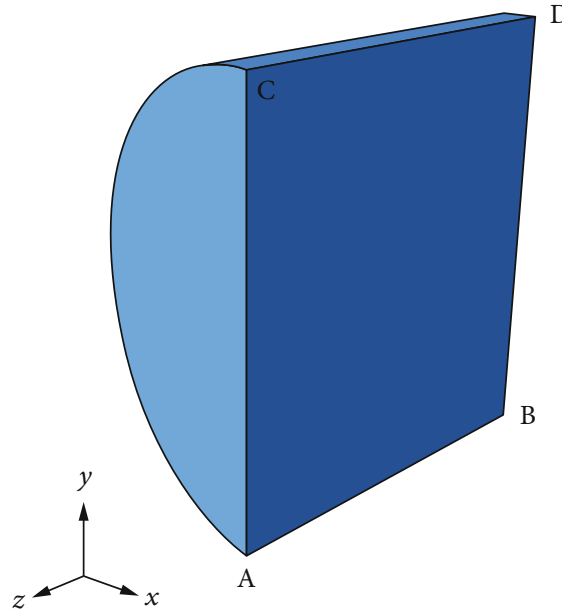

(a) $K=0 \%$

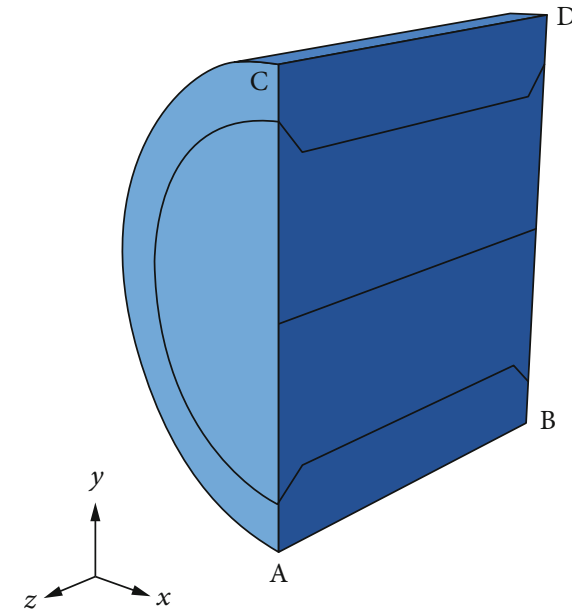

(b) $K=65 \%$

FIgURE 2: 3D models for solid rolling elements and elastic composite cylindrical rolling element with a filling degree of $60 \%$.

TABLE 1: Modal analysis of rolling elements.

\begin{tabular}{|c|c|c|c|c|c|}
\hline \multirow{2}{*}{ Order number } & \multicolumn{4}{|c|}{ Natural frequency (HZ) } & \multirow{2}{*}{ Vibration mode description } \\
\hline & $0 \%$ & $40 \%$ & $50 \%$ & $65 \%$ & \\
\hline 1 & 98,374 & 98,346 & 95,350 & 79,252 & Vibration in the $Y$ direction \\
\hline 2 & 294,760 & 167,456 & 167,037 & 161,644 & Bending vibration on the $Y Z$ plane \\
\hline 3 & 518,826 & 169,688 & 167,128 & 163,419 & Bending vibration on the $X Z$ plane \\
\hline 4 & 535,240 & 172,847 & 168,464 & 166,626 & Bending vibration at the center of the $Y Z$ plane \\
\hline 5 & 547,309 & 174,916 & 169,048 & 166,734 & Bending vibration on the $Y Z$ plane \\
\hline 6 & 602,203 & 176,296 & 170,527 & 166,781 & Vibration in the $X$ direction \\
\hline
\end{tabular}

\section{Transient Dynamic Characteristics}

3.1. Construction of the Finite Element Model. To analyze the response laws of solid rolling element and elastic composite cylindrical rolling element with filling degrees of 40\%, 50\% and $65 \%$, under impact loads, time-varying loads were applied on various rolling elements, as shown in Eq. (1). Impact loads were applied in the form of nodal loads on 
the edge $\mathrm{CD}$ of each finite element model. The boundary condition settings and meshing forms of various rolling elements were consistent with their modal analysis models.

$$
F(t)= \begin{cases}F_{0} & 0<t \leq t_{0} \\ 0 & t_{0}<t \leq t_{1}\end{cases}
$$

The selection of a suitable integration time step greatly affects the precision of the transient response solutions of rolling elements. To solve the dynamic responses of rolling elements under loads, a sufficiently small-time step should be selected, so as to achieve a higher calculation precision. However, an excessively small-time step usually consumes abundant computing resources. In contrast, an excessively large integration time step is often unable to meet the precision requirements of solving the dynamic responses of rolling elements. To strike a balance between computing resources and calculation precision, the integration time step is generally set as [16]:

$$
\Delta t=\frac{1}{20 f_{n}},
$$

where, $f_{n}$ is the sampling frequency.

In normal circumstances, radial loads are the dominant loads on rolling elements. Consequently, on the basis of the modal analysis results, as listed in Table 1, the natural frequency of the vibration in the $\mathrm{Y}$ direction, with practical engineering significance for various rollers, was adopted in this study, to determine the integration time step $\Delta t$.

3.2. Analysis Results and Discussion. Figure 3 illustrates the displacement response time-history curves at the central node of the loading edge CD of the finite element model, for solid cylindrical rolling element and elastic composite cylindrical rolling element with filling degrees of 40\%, 50\% and $65 \%$, under external load $F(t)$. According to Figure 3, the nodal displacement responses of solid cylindrical rolling element and elastic composite cylindrical rolling element with filling degrees of $40 \%, 50 \%$ and $65 \%$ include two stages, i.e., the loading stage ( $0 \mathrm{~s} \sim 0.25 \mathrm{~s}$ ) and the unloading stage (0.25 s 0.5 s). After a certain period of attenuation, around the equilibrium position, the nodal displacement tended to gradually stabilize at a constant value. In the loading stage (0 s 0.25 s), the maximum nodal displacement occurred at the instant of applying impact loads. After a certain time, the nodal displacement attenuated and oscillated around the equilibrium position, while tended to gradually stabilize at a constant value. Due to the effect of the embedding rate of PTFE on roller stiffness, different rollers have different equilibrium positions, in this stage. For solid cylindrical rolling elements and elastic composite cylindrical rolling element with filling degrees of $40 \%, 50 \%$ and $65 \%$, the coordinates of the displacement axes of the nodes, at the equilibrium position in the loading stage, were -0.03498 $\mathrm{mm},-0.04542 \mathrm{~mm},-0.06183 \mathrm{~mm}$ and $-0.09977 \mathrm{~mm}$, respectively. In the unloading stage $(0.25 \mathrm{~s} \sim 0.5 \mathrm{~s})$, the nodal displacements of the rolling elements increased rapidly, as a result of unloading. After some time had passed, the nodal displacement attenuated and oscillated around the equilibrium position $(0 \mathrm{~mm})$, just like in the loading stage, while gradually approached $0 \mathrm{~mm}$.

Figure 4 illustrates the energy changes of various models for solid cylindrical rolling element and elastic composite cylindrical rolling element with filling degrees of 40\%, 50\% and $65 \%$, under external load $F(t)$. Clearly, the energy levels of the rollers peaked at the instants of loading and unloading; solid cylindrical rolling element and elastic composite cylindrical rolling element with different filling degrees presented different peaks. Due to the action of damping in rolling element structures, the energy in the rolling elements dissipated, while energy levels showed a gradual transition from peak to $0 \mathrm{~mJ}$, in both loading and unloading stages.

\section{Calculation of Damping Ratios}

4.1. Analysis on Damped Free Vibration. Structural damping is a basic dynamic property of structures and an important structural parameter, describing energy dissipation in the vibration process $[17,18]$. On account of its complex mechanism, structural damping cannot be precisely ascertained, while it is generally equated as viscous damping. At present, the common methods used to solve viscous damping ratios include the free decay method, the frequency response method and the resonance amplification method. In this study, on the basis of the nodal displacement response and the low-damping characteristics of the rolling elements, damping ratios were calculated according to the free attenuation characteristics of the nodal displacements of solid cylindrical rolling element and elastic composite cylindrical rolling element with filling degrees of $40 \%, 50 \%$ and $65 \%$, after unloading.

For a damped structure, its free vibration equation is described as $[19,20]$ :

$$
\ddot{x}+2 n \dot{x}+\omega^{2} x=0
$$

Where, $2 n=c / m, n$ is the attenuation coefficient; $\omega$ is the natural frequency of vibration, whose general solution is $x$ ( $t)=C_{1} e^{r_{1} t}+C_{2} e^{r_{2} t}$; constants $C_{1}$ and $C_{2}$ are determined according to initial conditions.

The logarithmic decrement $\delta$ is:

$$
\delta \equiv \ln \frac{x_{n}}{x_{n+1}}=\frac{2 \pi \xi}{\sqrt{1-\xi^{2}}} .
$$

To guarantee high calculation precision, in a lowdamping structural system, generally wave crests with an interval of $m$ periods are selected for calculation:

$$
\delta \equiv \ln \frac{x_{n}}{x_{n+m}}=\frac{2 \pi m \xi}{\sqrt{1-\xi^{2}}} \approx 2 \pi m \xi .
$$




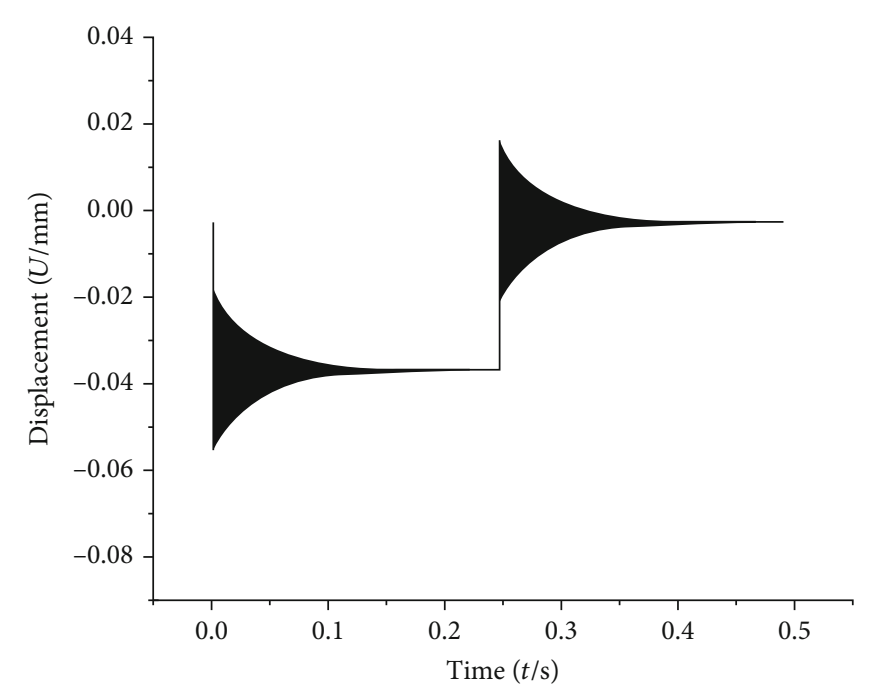

(a) $K=0 \%$

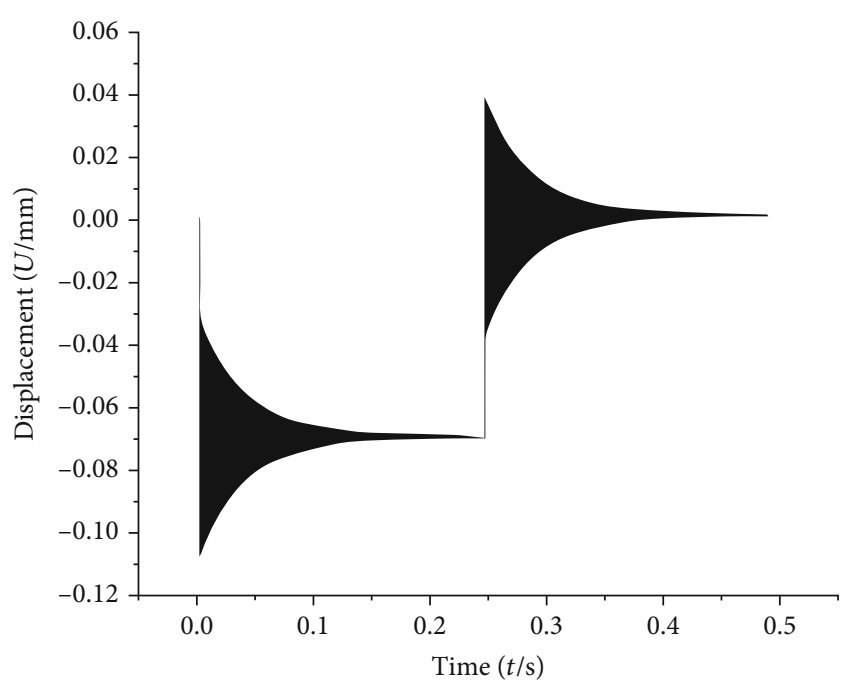

(c) $K=50 \%$

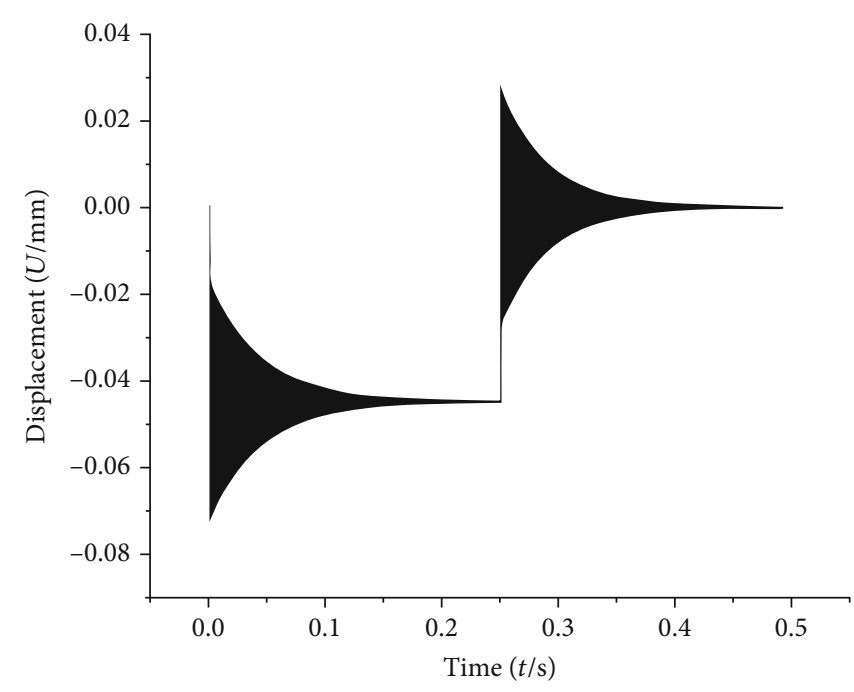

(b) $K=40 \%$

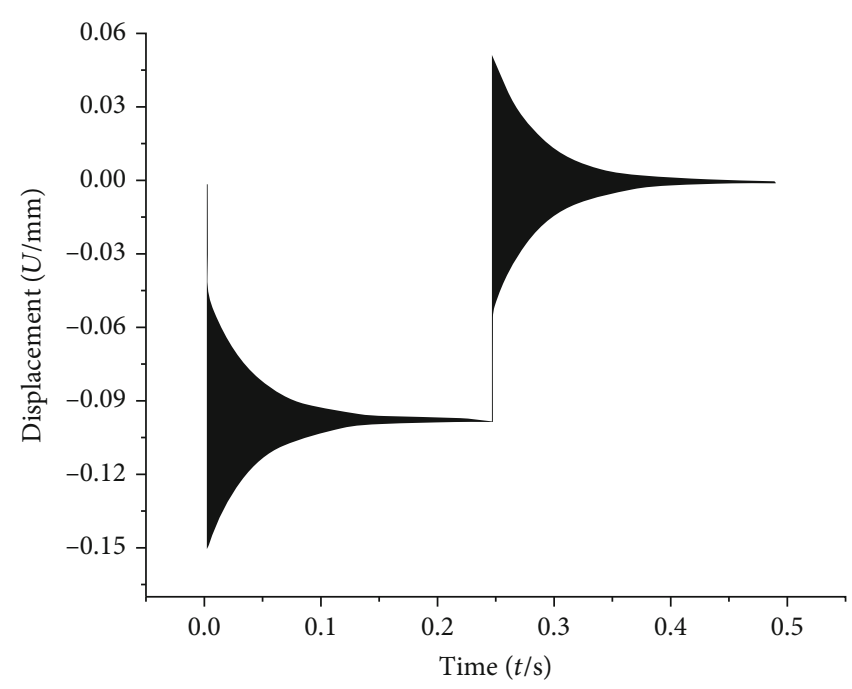

(d) $K=65 \%$

Figure 3: Displacement responses at the same node for solid rolling element and elastic composite cylindrical rolling element with different filling degrees.

Thus, the damping ratio is

$$
\xi=\frac{1}{2 \pi m} \ln \frac{x_{n}}{x_{n+m}} .
$$

4.2. Effects of Filling Degrees on Damping Ratios. To analyze the effects of filling degrees on the damping ratios of elastic composite cylindrical rolling element, the free attenuation curves of the nodal displacements of such an element with a filling degree of $40 \%$, after unloading, were considered as a case study. Damped vibration amplitudes of ten periods were adopted, while there was an interval of ten periods in each case. The damping ratios of elastic composite cylindrical rolling element, with a filling degree of $40 \%$, were calculated based on Eq. (10), deriving five damping ratios. To reduce calculation errors, the five damping ratios were averaged to acquire the final value. The calculation results of the damping ratios of elastic composite cylindrical rolling element with a filling degree of $40 \%$ are provided in Table 2 .

In the same vein, the damping ratios of other rolling elements were calculated using the same method. The results for damping ratios of solid cylindrical rolling element and elastic composite cylindrical rolling element with filling degrees of $40 \%, 50 \%$ and $65 \%$ are provided in Table 3 . The results in Table 3 show that, the damping ratios of rolling elements decreased, as the filling degree increased.

4.3. Effects of External Loads on Damping Ratios. To clarify the effects of external loads on the damping ratios of the rolling elements, the dynamic responses of solid rolling element and elastic composite cylindrical rolling element with a filling degree of $40 \%$, were analyzed, under different external loads, while the respective damping ratios were calculated, using the free attenuation curves of the nodal displacements, after unloading, as detailed in Table 4. 


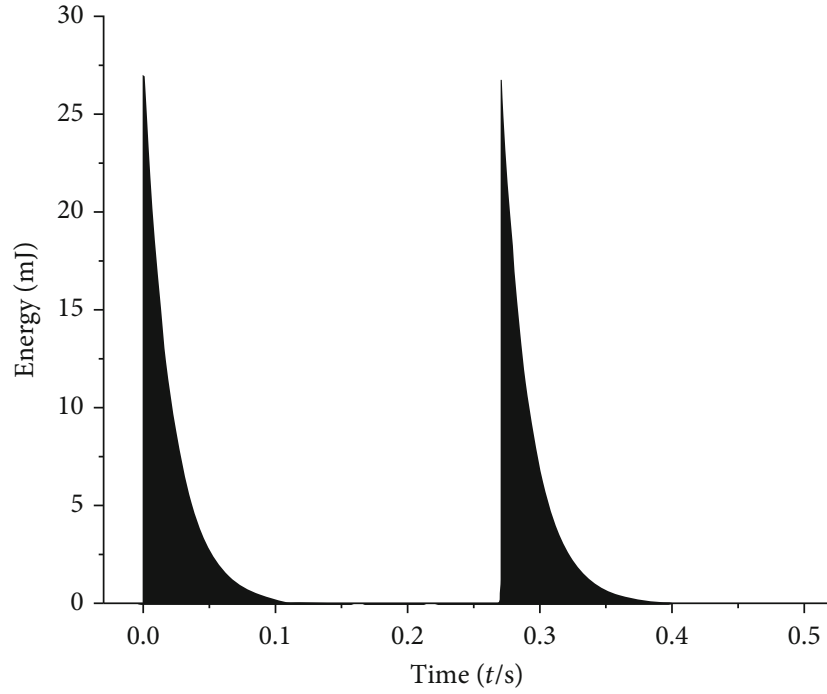

(a) $K=0 \%$

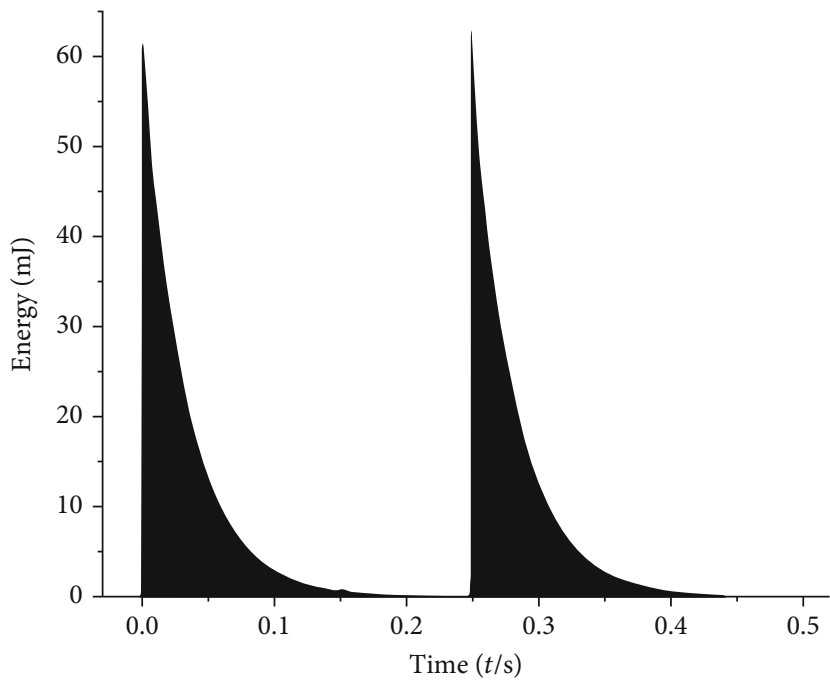

(c) $K=50 \%$

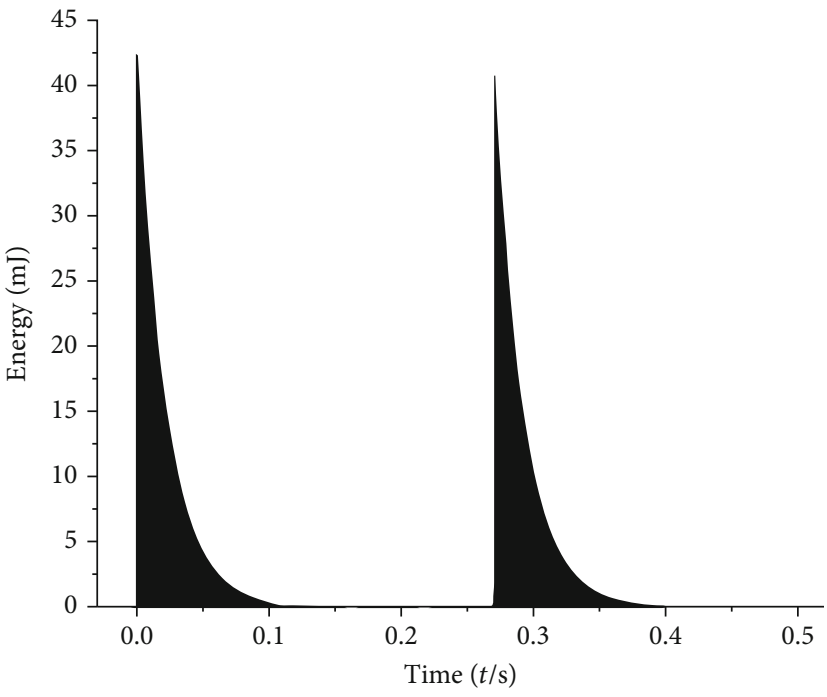

(b) $K=40 \%$

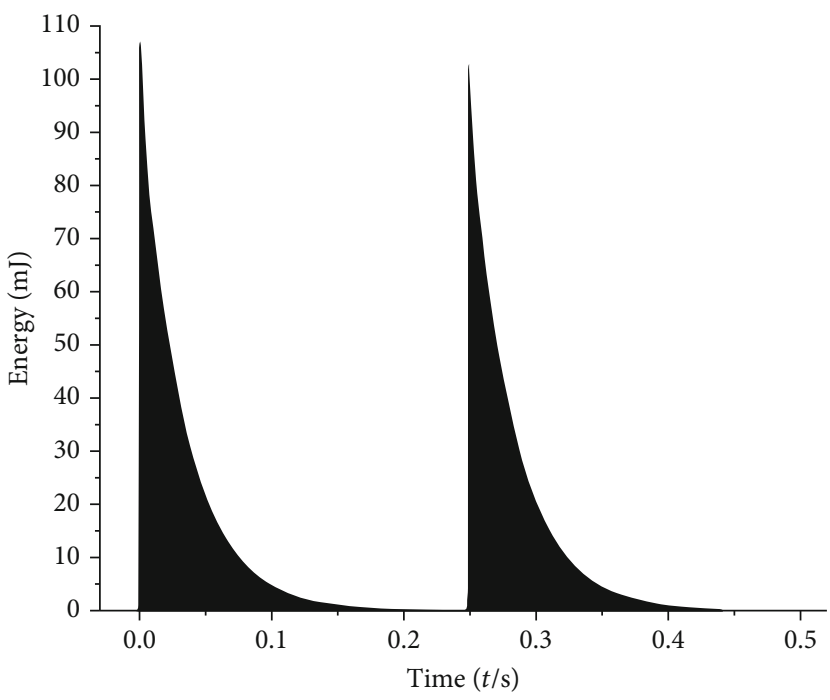

(d) $K=65 \%$

FIgURE 4: Energy changes of solid rolling element and elastic composite cylindrical rolling element with different filling degrees.

TABLE 2: Damping ratios of elastic composite cylindrical rolling element with a filling degree of $40 \%$.

\begin{tabular}{lcccc}
\hline No. & Time/s & Amplitude/mm & Damping ratio $\xi$ & Mean $\bar{\xi}$ \\
\hline$x_{10}$ & $2.74063 E-1$ & $1.41255 E-2$ & $7.39246 E-4$ & \\
$x_{20}$ & $2.75827 E-1$ & $1.34844 E-2$ & & \\
$x_{30}$ & $2.77624 E-1$ & $1.28658 E-2$ & $7.36879 E-4$ & \\
$x_{40}$ & $2.79454 E-1$ & $1.22837 E-2$ & & \\
$x_{50}$ & $2.81118 E-1$ & $1.17409 E-2$ & $7.35168 E-4$ & $7.37539 E-4$ \\
$x_{60}$ & $2.82882 E-1$ & $1.12109 E-2$ & & \\
$x_{70}$ & $2.84579 E-1$ & $1.07120 E-2$ & $7.34461 E-4$ & \\
$x_{80}$ & $2.86341 E-1$ & $1.02289 E-2$ & & \\
$x_{90}$ & $2.88105 E-1$ & $0.974892 E-2$ & $7.41940 E-4$ & \\
$x_{100}$ & $2.88870 E-1$ & $0.930488 E-2$ & & \\
\hline
\end{tabular}

According to Table 4, different external loads exerted non-significant effects on the damping ratios of solid cylindrical rolling element and elastic composite cylindrical rolling element with a filling degree of $40 \%$. The reason is that, structural damping is a natural characteristic of objects, unaffected by external loads. The consistency between calculation results and reality testifies to the validity of the above described calculation method.

4.4. Effects of Structural Dimensions on the Damping Ratios of Rolling Elements. To explore the effects of structural dimensions on the damping ratios of rolling elements, different types of rolling elements were selected, to analyze their dynamic responses, under external load $F(t)$ and calculate their damping ratios. Table 5 provides the calculation results for damping ratios of solid cylindrical rolling element and elastic composite cylindrical rolling element with a filling degree of $40 \%$, under different structural dimensions. 
TABLE 3: Damping ratios of solid cylindrical rolling element and elastic composite cylindrical rolling element with filling degrees of $40 \%$, $50 \%$, and $65 \%$.

\begin{tabular}{lcccc}
\hline Filling degree $K$ & $0 \%$ (solid) & $40 \%$ & $50 \%$ & $65 \%$ \\
\hline Damping ratio $\xi$ & $8.30611 E-4$ & $7.37539 E-4$ & $7.06547 E-4$ & $5.53694 E-4$ \\
\hline
\end{tabular}

TABLE 4: Damping ratios of solid cylindrical rolling element and elastic composite cylindrical rolling element with a filling degree of $40 \%$ under different loads.

\begin{tabular}{|c|c|c|c|c|c|}
\hline Load & $1.4 F_{0}$ & $1.2 F_{0}$ & $F_{0}$ & $0.8 F_{0}$ & $0.6 F_{0}$ \\
\hline Solid roller $(K=0 \%)$ & $8.34764 E-4$ & $8.29863 E-4$ & $8.30611 E-4$ & $8.322726 E-4$ & $8.33103 E-4$ \\
\hline Elastic roller $(K=40 \%)$ & $7.34805 E-4$ & $7.38427 E-4$ & $7.37539 E-4$ & $7.45153 E-4$ & $7.42097 E-4$ \\
\hline
\end{tabular}

TABLE 5: Damping ratios of solid cylindrical rolling element and elastic composite cylindrical rolling element with a filling degree of $40 \%$ under different structural dimensions.

\begin{tabular}{lcccc}
\hline Structural dimensions & $L=13.5, D=15$ & $L=28, D=44$ & $L=30, D=48$ & $L=32, D=32$ \\
\hline Solid roller $(K=0 \%)$ & $8.30611 E-4$ & $7.22631 E-4$ & $7.18302 E-4$ & $7.40517 E-4$ \\
Elastic roller $(K=40 \%)$ & $7.37539 E-4$ & $6.72712 E-4$ & $6.57347 E-4$ & $7.88034 E-4$ \\
\hline
\end{tabular}

Clearly, rollers with different structural dimensions had different damping ratios.

\section{Conclusions}

(1) Elastic composite cylindrical rolling element with a higher filling degree had lower natural frequencies of various orders. The natural frequencies of various orders of solid cylindrical rolling element were higher than those of elastic composite cylindrical rolling element.

(2) Under impact loads, the nodal displacements of the rolling element attenuated and oscillated around an equilibrium position, in both loading and unloading stages, while it tended to gradually stabilize at a constant value.

(3) Elastic composite cylindrical rolling element of different types had different damping ratios. In the case of elastic composite cylindrical rolling element of the same type, a higher filling degree meant a lower damping ratio.

(4) For the dynamic analysis of elastic composite cylindrical roller bearing, the complex working conditions of rotor system and the interaction between bearing and rotor need to be considered. The dynamic response of the whole system needs to be further discussed.

\section{Data Availability}

The data are in the article.

\section{Conflicts of Interest}

We declare that we do not have any commercial or associative interest that represents a conflict of interest in connection with the work submitted.

\section{Acknowledgments}

This work was supported by the National Natural Science Foundation of China (51175168) and the Hunan Natural Science Foundation in China (2021JJ50054).

\section{References}

[1] Y. Liu, B. Wang, and S. Yang, "Nonlinear dynamic Behaviors analysis of the bearing rotor system with outer ring faults in the high-speed train," Journal of Mechanical Engineering, vol. 54, no. 8, pp. 17-25, 2018.

[2] J. V. Poplawski, S. M. Peters, and E. V. Zaretsky, "Effect of roller profile on cylindrical roller bearing life prediction-part II comparison of roller profiles," Tribology Transactions, vol. 44, no. 3, pp. 417-427, 2001.

[3] M. T. Hanson and L. M. Keer, "Mechanics of edge effects on frictionlesscontacts," International Journal of Solids and Structures, vol. 32, no. 3-4, pp. 391-405, 1995.

[4] M. J. Hartnett, "The analysis of contact stresses in rolling element bearings," Journal of Lubrication Technology, vol. 101, no. 1, pp. 105-109, 1979.

[5] S. Ljasenko, N. Lohse, and L. Justham, "Dynamic vs dedicated automation systems - a study in large structure assembly," Production \& Manufacturing Research, vol. 8, no. 1, pp. 35-58, 2020.

[6] V. A. Pikovskii, V. G. Kustov, E. V. Leonov, V. V. Shashkin, and I. V. Zinov'ev, "Study of the working capacity of highvelocity radial bearings with hollow rollers," Strength of Materials, vol. 3, no. 10, pp. 1178-1185, 1971. 
[7] C. S. C. Murthy and A. R. Rao, "Mechanics and behaviour of hollow cylindrical members in rolling contact," Wear, vol. 87, no. 3, pp. 287-296, 1983.

[8] W. M. Abu Jadayil and N. M. Jaber, "Numerical prediction of optimum hollowness and material of hollow rollers under combined loading," Materials and Design, vol. 31, no. 3, pp. 1490-1496, 2010.

[9] Q. Yao, W. Yang, J. Yu, and R. Zhang, "Research on structure design of elastic composite cylindrical roller bearing," China Mechanical Engineering, vol. 23, no. 24, pp. 2899-2902, 2012.

[10] J. Yu, W. Yang, C. Li, and Q. Yao, "Machining technology for elastic composite cylindrical rollers," China Mechanical Engineering, vol. 26, no. 12, pp. 1616-1621, 2015.

[11] Q. S. Yao, W. Yang, D. J. Yu et al., "Bending stress of rolling element in elastic composite cylindrical roller bearing," Journal of Central South University, vol. 20, no. 12, pp. 34373444, 2013.

[12] Y. Qishui, Y. Wen, L. Chao, and Y. Jianghong, "A design method for a new type of cylindrical roller bearing based on edge effect," Open Mechanical Engineering Journal, vol. 10, no. 1, pp. 98-108, 2016.

[13] J. Yu, W. Yang, C. Li, and Q. Yao, "Contact analysis of elastic composite cylindrical roller bearing," Journal of Mechanical Strength., vol. 37, no. 6, pp. 1099-1105, 2015.

[14] J. Yu, L. Xiang, W. Yang, C. Li, Y. Deng, and Q. Yao, “Modal and harmonic response analysis of a rolling bearing coupled by rigid and flexible materials," Materials Express, vol. 9, no. 9, pp. 1017-1024, 2019.

[15] C. Singh and J. S. Saini, "Algorithms for accurate and fast plotting of contour surfaces in 3D using hexahedral elements," Journal of the Institution of Engineers, vol. 97, no. 3, pp. 389405, 2016.

[16] W. Li, C. Pan, R. Wang, and X. Zhang, "Dynamic analysis of structural damping of solid roller and hollow roller," Journal of Vibration and Shock., vol. 28, no. 12, pp. 43-46,201, 2009.

[17] A. Yixue, The damping characteristics of large civil structures, Wuhan University of Technology, Wuhan, 2011.

[18] C. G. Cooley, T. Q. Tran, and T. Chai, "Comparison of viscous and structural damping models for piezoelectric vibration energy harvesters," Mechanical Systems and Signal Processing, vol. 110, pp. 130-138, 2018.

[19] S. Hongyu, Structural Dynamics, Hefei University of Technology Press, Hefei, 2nd edition, 2007.

[20] J. A. Little and B. P. Mann, "Optimizing logarithmic decrement damping estimation via uncertainty analysis," Special Topics in Structural Dynamics \& Experimental Techniques, Volume 5. Conference Proceedings of the Society for Experimental Mechanics Series, N. Dervilis, Ed., , pp. 19-22, Springer, Cham, 2020. 